\title{
The Affect Heuristic in Judgments of Risks and Benefits
}

\author{
MELISSA L. FINUCANE, ${ }^{1 *}$ ALI ALHAKAMI, ${ }^{2}$ PAUL SLOVIC ${ }^{1}$ \\ and STEPHEN M. JOHNSON ${ }^{1}$ \\ ${ }^{1}$ Decision Research, Eugene, OR, USA \\ 2Imam Muhammad Ibn Saud Islamic University Psychology Department, \\ Saudi Arabia
}

\begin{abstract}
This paper re-examines the commonly observed inverse relationship between perceived risk and perceived benefit. We propose that this relationship occurs because people rely on affect when judging the risk and benefit of specific hazards. Evidence supporting this proposal is obtained in two experimental studies. Study 1 investigated the inverse relationship between risk and benefit judgments under a time-pressure condition designed to limit the use of analytic thought and enhance the reliance on affect. As expected, the inverse relationship was strengthened when time pressure was introduced. Study 2 tested and confirmed the hypothesis that providing information designed to alter the favorability of one's overall affective evaluation of an item (say nuclear power) would systematically change the risk and benefit judgments for that item. Both studies suggest that people seem prone to using an 'affect heuristic' which improves judgmental efficiency by deriving both risk and benefit evaluations from a common source - affective reactions to the stimulus item. Copyright (C) 2000 John Wiley \& Sons, Ltd.
\end{abstract}

KEY WORDS affect heuristic; judgment; perception of risk; perception of benefit

\begin{abstract}
Although affect has long played a key role in many behavioral theories, it has rarely been recognized as an important component of human judgment and decision making. Perhaps befitting its rationalistic origins, the main focus of descriptive decision research has been cognitive, rather than affective. When principles of utility maximization appeared to be descriptively inadequate, Simon (1956) oriented the field toward problem solving and information-processing models based upon bounded rationality and concepts such as satisficing (as opposed to maximizing). The work of Tversky and Kahneman (1974) demonstrated how boundedly rational individuals employed heuristics such as availability, representiveness, and anchoring and adjustment to make judgments and how they used simplified strategies such
\end{abstract}

\footnotetext{
* Correspondence to: Melissa L. Finucane, Decision Research, 1201 Oak Street, Eugene, OR 97401, USA.

E-mail: finucane@decisionresearch.org

Contract grant sponsor: US National Science Foundation.

Contract grant number: SBR 9422754.

Contract grant number: SBR 9709307.
}

CCC 0894-3257/2000/010001-17\$17.50

Copyright (C) 2000 John Wiley \& Sons, Ltd. 
as 'elimination by aspects' to make choices (Tversky, 1972). Other investigators elaborated the cognitive strategies underlying judgment and choice through models of constructed preferences (Slovic, 1995; Payne, Bettman, and Johnson, 1992), dominance structuring (Montgomery, 1983), and comparative advantages (Shafir, Osherson, and Smith, 1989). In 1993, an entire issue of the journal Cognition was dedicated to the topic of Reason-Based Choice, in which it was argued that 'Decisions ... are often reached by focusing on reasons that justify the selection of one option over another' (Shafir, Simonson, and Tversky, 1993, p.34). Similarly, a recent state-of-the-art review was titled 'Decision making from a cognitive perspective' (Busemeyer, Hastie, and Medin, 1995). In keeping with its title, it contained almost no references to the influence of affect on decisions.

Despite this cognitive emphasis, the importance of affect ${ }^{1}$ is being acknowledged increasingly by decision researchers. A limited role for affect was acknowledged by Shafir et al. (1993) who conceded that 'People's choices may occasionally stem from affective judgments that preclude a thorough evaluation of the options' (p. 32, emphasis added).

A strong early proponent of the importance of affect in decision making was Zajonc (1980), who argued that affective reactions to stimuli are often the very first reactions, occurring automatically and subsequently guiding information processing and judgment. According to Zajonc, all perceptions contain some affect. 'We do not just see "A house": We see a handsome house, an ugly house, or a pretentious house' (p. 154). He later adds, 'We sometimes delude ourselves that we proceed in a rational manner and weigh all the pros and cons of the various alternatives. But this is probably seldom the actual case. Quite often "I decided in favor of X" is no more than "I liked X" ... We buy the cars we "like", choose the jobs and houses we find "attractive", and then justify these choices by various reasons ...' (p. 155).

One of the most comprehensive and dramatic theoretical accounts of the role of affect in decision making is presented in Damasio's (1994) somatic marker hypothesis. In seeking to determine 'what in the brain allows humans to behave rationally', Damasio argues that thought is made largely from images, broadly construed to include perceptual and symbolic representations. A lifetime of learning leads to these images to become 'marked' by positive and negative feelings linked directly or indirectly to somatic or bodily states. When a negative somatic marker is linked to an image of a future outcome, it sounds an alarm. When a positive marker is associated with the outcome image, it becomes a beacon of incentive. Damasio hypothesized that somatic markers increase the accuracy and efficiency of the decision process and the absence of such markers, observed in people with certain types of brain damage, degrades decision performance.

Other theorists give affect a direct role in motivating behavior, asserting or implying that we integrate positive and negative feelings according to some sort of automatic, rapid 'affective algebra', whose operations and rules remain to be discovered. Epstein's (1994) view on this is clear, though he gives no clue as to how feelings are integrated:

The experiential system is assumed to be intimately associated with the experience of affect, ... which refer[s] to subtle feelings of which people are often unaware. When a person responds to an emotionally significant event ... the experiential system automatically searches its memory banks for related events, including their emotional accompaniments ... If the activated feelings are pleasant, they motivate actions and thoughts anticipated to reproduce the feelings. If the feelings are unpleasant, they motivate actions and thoughts anticipated to avoid the feelings (p. 716).

\footnotetext{
${ }^{1}$ Affect may be viewed as a feeling state that people experience, such as happiness or sadness. It may also be viewed as a quality (e.g. goodness or badness) associated with a stimulus. These two conceptions tend to be related. This paper will be concerned with both of these aspects of affect.
} 
Also emphasizing the motivational role of affect, Mowrer (1960a, b) conceptualizes conditioned emotional responses to images as prospective gains and losses that directly 'guide and control performance in a generally sensible adaptive manner' (1960a, p. 30). He criticizes theorists who postulate purely cognitive variables such as expectancies as intervening between stimulus and response, reiterating the concern of Guthrie (1952) that we must be careful not to leave the organism at the choice point 'lost in thought'. Mowrer's solution is to view expectancies more dynamically (as conditioned emotions such as hopes and fears) which serve as motivating states leading to action.

Despite the increasing popularity of affect in research programs and recent attempts to acknowledge the importance of the interplay between affect and cognition, little progress has been made in developing a theory about the role of affect in judgment and decision making. Drawing on ideas about affect marking images (e.g. Damasio, 1994), which in turn motivates behavior (e.g. Epstein, 1994; Mowrer, 1960a, b), we propose that affect is an essential component in many forms of judgment and decision making. The ideas articulated below are intended as a first step toward encouraging the development of theory about, and methods for exposing, the role of affect in judgment.

The basic tenet in this paper is that images, marked by positive and negative affective feelings, guide judgment and decision making. ${ }^{2}$ Specifically, we propose that people use an affect heuristic to make judgments. That is, representations of objects and events in people's minds are tagged to varying degrees with affect. People consult or refer to an 'affective pool' (containing all the positive and negative tags associated with the representations consciously or unconsciously) in the process of making judgments. Just as imaginability, memorability, and similarity serve as cues for probability judgments (e.g. the availability and representativeness heuristics), affect may serve as a cue for many important judgments. Using an overall, readily available affective impression can be far easier - more efficient - than weighing the pros and cons or retrieving from memory many relevant examples, especially when the required judgment or decision is complex or mental resources are limited. This characterization of a mental short-cut leads us to label the use of affect an 'heuristic'.

To illustrate the role of affect in judgment, and show how we can ascertain people's use of the affect heuristic, we focus on a specific problem, namely, trying to explain the often observed inverse relationship between judgments of risk and benefit.

\section{USING THE AFFECT HEURISTIC TO EXPLAIN THE INVERSE RELATIONSHIP BETWEEN PERCEIVED RISK AND PERCEIVED BENEFIT}

Within an analytic view of judgment and decision making, risk and benefit are distinct concepts. The nature of the gains attained from pursuit of a hazardous activity or technology is qualitatively different from the nature of the risks. For instance, the benefit gained from using roller blades (e.g. entertaining pastime) is different from the risk (e.g. injury from a car collision). Driving to work, eating beef, and using a cellular phone are other examples of activities with distinct benefits and risks. Though distinct, risks and benefits generally tend to be positively correlated. Whereas activities that bring great benefits may be high or low in risk, activities that are low in benefit are unlikely to be high in risk (if they were, they would be proscribed), suggesting the positive correlation in Exhibit 1.

Although risk and benefit may be positively correlated in the environment, numerous studies have shown them to be negatively related in people's minds. For example, Fischhoff et al. (1978), Slovic et al. (1991), and McDaniels et al. (1997) reported that for many hazards the greater the perceived benefit,

\footnotetext{
${ }^{2}$ This is not meant to imply that only affect influences judgment and decision making. Clearly, many other cognitive operations have been shown to be important (Payne, Bettman, and Johnson, 1993) and need to be integrated with our emerging understanding of the role of affect in judgments.
} 


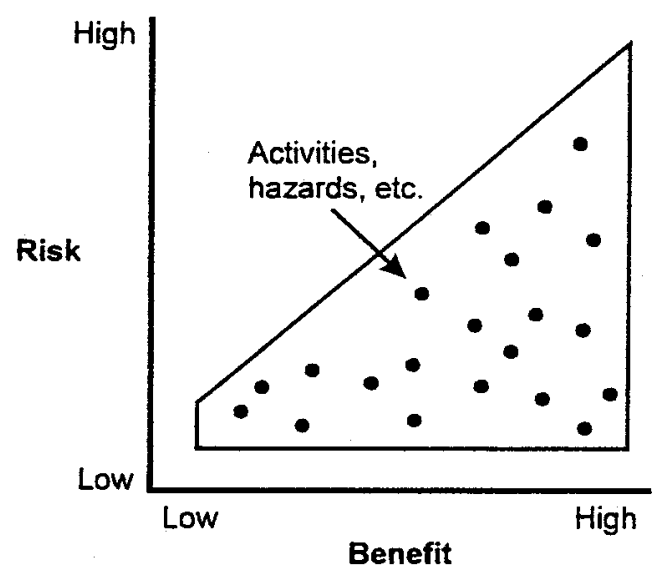

Exhibit 1. Hypothesized relationship between risk and benefit in the environment. Risk and benefit are positively correlated across activities

the lower the perceived risk, and vice versa. Smoking, alcoholic beverages, and food additives tend to be seen as very high in risk and relatively low in benefit, while vaccines, antibiotics, and X-rays tend to be seen as very high in benefit and relatively low in risk.

A study by Alhakami and Slovic (1994) suggested that risk and benefit may be inversely related in people's minds because an affective feeling is referred to when the risk or benefit of specific hazards is judged. Specifically, Alhakami and Slovic observed that the relationship between perceived risk and perceived benefit was linked to an individual's general affective evaluation of a hazard. If an activity was 'liked', people tended to judge its risks as low and its benefits as high. If the activity was 'disliked', the judgments were opposite - high risk and low benefit. The model implied by this behavior is similar to the model Zajonc proposed in 1980. Our model assumes that affect comes prior to, and directs, judgments of risk and benefit. See Exhibit 2.

Despite the evidence in support of the role of affect in judgment and decision making, a cognitive interpretation of Alhakami and Slovic's (1994) results cannot be excluded completely. Their experimental design cannot rule out the possibility that risk and benefit judgments are correlated negatively because individuals approach the judgment tasks analytically, producing a 'net riskiness' or 'net benefit' judgment rather than independent judgments of risk and benefit. That is, individuals may be making judgments (regardless of whether the rating scale focuses only on risk or on benefit) by deliberating on what the net difference between risk and benefit is for any particular item.

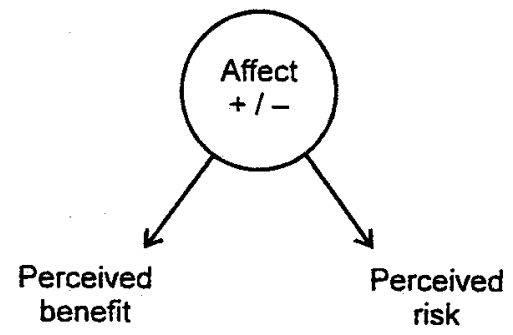

Exhibit 2. A model of the affect heuristic explaining the risk/benefit confounding observed by Alhakami and Slovic (1994). Judgments of risk and benefit are assumed to be derived by reference to an overall affective evaluation of the stimulus item 


\section{STUDY 1: RISK AND BENEFIT JUDGMENTS UNDER TIME PRESSURE}

Study 1 attempted to rule out the possibility of a cognitive explanation of the inverse risk/benefit relationship by using a 'time-pressure' methodology (see Benson and Beach, 1996; Ordóñez and Benson, 1997). Inducing time pressure when individuals are making judgments has two main consequences compatible with the goal of exposing the importance of affect in judgment. As outlined by Maule and Svenson (1993), perception that time is limited may influence judgment by:

(1) Inducing affective changes via a generally increased arousal level (making 'hot' affective processes more salient than analytical cognitive processes to individuals); and

(2) Reducing cognitive resources available for analytic deliberation during risk and benefit judgments (because the awareness of time pressure demands that resources are allocated to monitoring the time available).

Most time-pressure research has examined how cognitive processes and outcomes change as a result of the minimization of cognitive effort (see Beach and Mitchell, 1978; Edland and Svenson, 1993; Kerstholt, 1994; Payne, Bettman, and Johnson, 1988; Svenson, Edland, and Slovic, 1990). However, from our perspective the methodology is relevant because of its potential for manipulating individuals' heuristic reliance on affect when making judgments.

So far, few researchers have exploited the potential of time-pressure studies to highlight the use of affectively-based heuristics. One exception was an examination of the influence of attitudes and stereotypes on judgments of people belonging to particular social categories by Dijker and Koomen (1996). They found greater differences between 'ingroup' and 'outgroup' targets when judgments were made under time pressure, suggesting that when processing is difficult people tend to use an 'acceptability heuristic' (i.e. the tendency to produce socially acceptable judgments; see Tetlock, Skitka, and Boettger, 1989). Dijker and Koomen reported that under time pressure subjects seemed to base their judgments on both positive and negative aspects of their attitudes; they concluded that emotional responses toward social groups are important components in judgments. Similarly, we anticipated that reliance on affect in the domain of judgments about hazards could be exposed by inducing time pressure.

According to the affect heuristic, people may judge the risks and benefits of hazards by accessing a pool of positive and negative feelings they associate with the hazards. The affect heuristic is more efficient than analytic processing. Thus, compared with individuals under no time pressure, we expected those under time pressure to rely more heavily on affect because efficiency is important. Stronger negative correlations between risk and benefit judgments were expected for participants in the timepressure than in the no-time-pressure condition.

\section{Method}

\section{Participants}

Fifty-four first-year Psychology students from the University of Western Australia (mean age 19 years) participated in the study for course credit. Females constituted $78 \%$ of the sample.

\section{Design}

Participants were randomly assigned to one of two conditions (time pressure or no time pressure) and to one of two counterbalancing orders (risk judgments followed by benefit judgments, or vice versa). 


\section{Apparatus}

Stimuli were presented via computer, using MetaCard 2.1.2 on an IBM 486 (DX-4100) with a 15-inch monitor.

\section{Stimuli and procedure}

All instructions were presented on the computer monitor. First, participants learned that they would be making judgments about the risk (or benefit) of various activities and technologies for Australian society as a whole, on a 7-point scale ranging from not at all risky (beneficial) to very risky (beneficial). The scale was shown and the end-point labels flashed in yellow to attract participants' attention. The participants were then shown how to move the mouse and click on the scale to make a rating. For the time-pressure condition, the instructions next indicated, in capital letters, that only a short time would be available for participants to click on the scale for each item and that a response must be made before a clock shown at the bottom of the screen ticked down completely from green to red. A demonstration of the clock ticking down was given. For the no-time-pressure condition, participants were instructed to take as much time as they wanted to complete the ratings; no clock was present.

Participants were presented with eight hazardous facilities or activities for rating in practice trials, and 23 items for the experimental trials (e.g. cars, chemical plants). The beginning of each trial was signaled by the computer with the sound of a bell, at which time the name of the item was shown in the middle of the monitor (and the clock in the time-pressure condition began to tick down). Pilot testing $(n=10)$ under the no-time-pressure condition showed that about 5.2 seconds was one standard deviation faster than the mean times for risk and benefit ratings. Thus, in the time-pressure condition the clock was set to run out of time after 5.2 seconds for each item, at which point a yellow sign flashed above the scale saying 'You MUST click on the scale NOW', and the computer made a beeping sound until a rating was made.

Each participant received the items in a different random order. When all items had been rated on the first scale (either risk or benefit), the instructions were shown for the second (benefit or risk) scale, and all items were presented in a different random order again for rating.

\section{Results}

\section{Manipulation check}

As expected, participants in the time-pressure condition took significantly less time to do the risk judgments than did participants in the no-time-pressure condition $(M=101.24$ seconds, $S D=15.94$ versus $M=127.27$ seconds, $S D=29.12) ; t(52)=4.11, p<0.001$. The same was true for the benefit judgments $(M=100.71$ seconds, $S D=14.16$ versus $M=126.57$ seconds, $S D=34.57) ; t(52)=3.65$, $p<0.001$.

\section{Correlations}

The correlation between judged risk and judged benefit across the 23 items based on mean ratings was -0.80 for the time-pressure condition and -0.75 for the no-time-pressure condition. Both these correlations are heavily influenced by two extreme items, cigarettes (Benefit $M=1.29$, Risk $M=6.22$ for time pressure; Benefit $M=1.79$, Risk $M=6.33$ for no time pressure) and solar power (Benefit $M=6.26$, Risk $M=1.68$ for time pressure; Benefit $M=6.21$, Risk $M=1.55$ for no time pressure). There were no other means less than 2.37 and only two other means greater than 5.88 (air travel, Benefit $M=6.10$ for no time pressure and Risk $M=6.02$ for time pressure). Nonetheless, correlations 
calculated after eliminating cigarettes and solar power showed the same results: negative relationships between judged risk and judged benefit, with correlations of -0.69 under time pressure and -0.62 under no time pressure.

Correlations calculated on each individual's ratings across the 21 items showed the same pattern. For the time-pressure condition, the mean correlation was -0.45 ; the range was from -0.95 to +0.28 ; 27 of the 28 participants' correlations in this condition were negative $(96 \%)$. For the no-time-pressure condition, the mean correlation was -0.33 ; the range was from -0.73 to $+0.30 ; 22$ of the 26 participants' correlations were negative $(85 \%)$. The difference between the two mean correlations approached significance; $t(52)=1.64, p=0.05$, one-tailed.

Another way of looking at these data is via individual differences. If people use the affect heuristic, then a person who has a positive feeling about, say, Cellular Phones, will rate it higher on benefit and lower on risk than will another person whose affect is not so positive. This will induce a negative correlation between risk and benefit ratings for Cellular Phones across participants.

As shown in Exhibit 3, correlations across participants between rated risk and rated benefit were negative for all but one of the 23 items in the time-pressure condition, and for all but four items in the no-time-pressure condition. As expected, the correlations were more strongly negative under time pressure than under no time pressure for most items (19 out of 23). For the time-pressure condition, 13 correlations were significantly negative (eight at the 0.01 level, and five at the 0.05 level), while only

Exhibit 3. Correlations across participants between perceived risk and perceived benefit under time-pressure $(N=28)$ and no-timepressure $(N=26)$ conditions.

\begin{tabular}{lcc}
\hline Item & Time pressure & No time pressure \\
\hline Alcoholic beverages & $-0.71^{* *}$ & 0.07 \\
Water fluoridation & $-0.68^{* *}$ & -0.33 \\
Chemical plants & $-0.62^{* *}$ & -0.10 \\
Eating beef & $-0.53^{* *}$ & -0.30 \\
Food preservatives & $-0.52^{* *}$ & -0.24 \\
Cars & $-0.48^{* *}$ & $-0.36^{*}$ \\
Cigarettes & $-0.48^{* *}$ & -0.24 \\
Pesticides & $-0.47^{* *}$ & -0.07 \\
Natural gas & $-0.41^{*}$ & 0.13 \\
Chemical fertilizers & $-0.41^{*}$ & -0.07 \\
Explosives & $-0.39^{*}$ & -0.10 \\
Cellular phones & $-0.36^{*}$ & $-0.44^{*}$ \\
Food irradiation & $-0.35^{*}$ & -0.01 \\
Roller blades & -0.31 & -0.02 \\
Nuclear power plants & -0.30 & -0.07 \\
Surfing & -0.28 & 0.01 \\
Swimming pools & -0.27 & -0.28 \\
Solar power & -0.27 & -0.03 \\
Railroads & -0.25 & -0.02 \\
Air travel & -0.22 & 0.21 \\
Motorcycles & -0.20 & -0.16 \\
Microwave ovens & -0.06 & -0.23 \\
Bicycles & 0.02 & -0.04 \\
Mean $r$ & -0.37 & -0.12 \\
\hline & &
\end{tabular}

$* p<0.05$ (one-tailed)

$* * p<0.01$ (one-tailed) 
two items showed a significant negative correlation for the no-time-pressure condition. The highest negative correlations under time pressure were found for alcoholic beverages $(r=-0.71)$, water fluoridation $(r=-0.68)$, chemical plants $(r=-0.62)$, eating beef $(r=-0.53)$, food preservatives $(r=-0.52)$, cars $(r=-0.48)$, cigarettes $(r=-0.48)$, and pesticides $(r=-0.47)$. In contrast, the highest negative correlations under no time pressure were more modest, including cellular phones $(r=-0.44)$, cars $(r=-0.36)$, and water fluoridation $(r=-0.33)$; see Exhibit 3. At the item level, the difference between the correlation under time pressure and the correlation under no time pressure was statistically significant for alcoholic beverages $(p<0.001)$, and for water fluoridation, chemical plants, natural gas, and pesticides $(p<0.05)$.

\section{Discussion}

Study 1 investigated the inverse relationship between risk and benefit judgments under conditions designed to limit the use of analytic thought and enhance the use of the affect heuristic. As expected, we found that the inverse relationship strengthened when time pressure was introduced. The stronger inverse relationship under time pressure was demonstrated in terms of more negative correlations between perceived benefit and perceived risk, within individuals over hazards and within hazards over individuals. The results are consistent with theories suggesting that people use affect to make judgments (Zajonc, 1980) and that affect is an important evaluation mechanism in risk perception (e.g. Alhakami and Slovic, 1994; Peters and Slovic, 1996; Slovic, 1997). ${ }^{3}$

Reliance on the affect heuristic seems to be exposed more clearly when people's opportunity for analytic deliberation is reduced and an efficient mode of judgment is needed. The results are consistent with Dijker and Koomen's (1996) report that time pressure reduces people's use of data-driven, attribute-based processing strategies and increases reliance on a more holistically evaluative strategy (in their case, attitudes). Although Dijker and Koomen refer to reliance on attitudes as a schemadriven strategy, which seems to have a cognitive connotation, their discussion underlines the importance of considering the affective components (emotional responses) of attitudes that affect judgments. Likewise, we suggest that reliance on affective processes to make quick judgments when cognitive processing is difficult is exhibited in our time-pressure condition and is an underexplored explanation of time-pressure effects.

Finally, of note is that the correlations found in Study 1 in the no-time-pressure condition for many items are smaller (i.e. less negative) than those found previously (e.g. water fluoridation; Alhakami and Slovic, 1994). The discrepancies may be due to methodological differences. In the present study we urged participants in the no-time-pressure condition 'to take as much time as desired', whereas participants in the Alhakami and Slovic study worked quickly through the ratings as part of a longer experiment. Making the task part of a larger set of demands may implicitly induce some sense of time pressure for participants. Cultural differences may also have contributed to the results. Alhakami and Slovic used American participants, but the present study was conducted in Australia where the risks and benefits of hazards may be experienced or perceived differently from the risks and benefits found in an American context (Finucane and Maybery, 1996; Rohrmann, 1994).

\footnotetext{
${ }^{3}$ A perceptive reviewer of this manuscript has questioned whether the results we observed may have been due to simple mechanical factors such as smaller movements from starting points or anchors in the time-pressure condition. We believe this to be unlikely because there was no anchor to start from for each trial, and because there is no obvious relationship between the physical demands of the task and the changes in response necessary to produce increased negative correlations under time pressure.
} 


\section{STUDY 2: MANIPULATING AFFECT BY PROVIDING RISK AND BENEFIT INFORMATION}

Study 1 tested the affect heuristic by experimentally manipulating time pressure to force greater reliance on affect. Study 2 carried out another, but very different, experimental test of the affect model. The basic idea is simple. If people consult their overall affective evaluation of an item (say, nuclear power) when judging its risk and benefit, then raising or lowering the favorability of the affective impression should alter both the risk and benefit judgments derived from that impression. That is, we expect risk and benefit judgments for a hazard to be congruent with the overall affective evaluation of the hazard.

One way to alter the favourability of the overall impression is through provision of information. For example, nuclear power could take on a more favourable affective evaluation as a result of information indicating that it has high benefit or, alternatively, that it has low risk.

According to the affect model, information indicating that the benefit is high should lead to a more favorable affective impression and thus to lower judgments of risk (because risk would be derived from the more favorable overall impression and a more attractive technology would be judged to have lower risk). Similarly, information that the risk is low should lead to an inference that the benefit is high (again because the technology has been made more attractive overall). These two predictions are summarized in parts A and B of Exhibit 4 and in rows 1 and 4 of Exhibit 5. In parallel fashion, overall positive affect towards nuclear power could be decreased by information indicating that benefit is low or risk is high, as shown in parts $\mathrm{C}$ and $\mathrm{D}$ of Exhibit 4. The model predicts that decreasing the overall affective favorability of nuclear power by decreasing perceived benefit would lead to an increase in

A

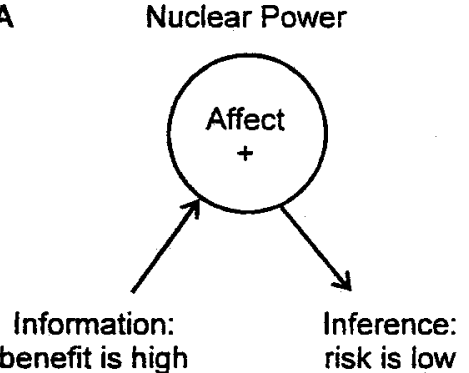

C
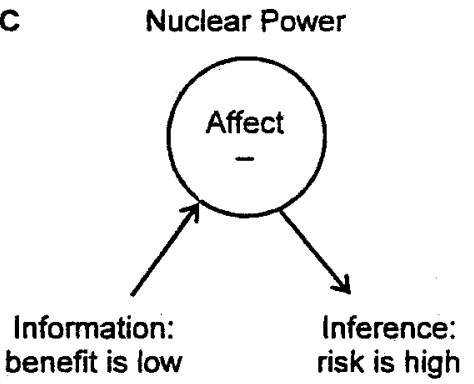

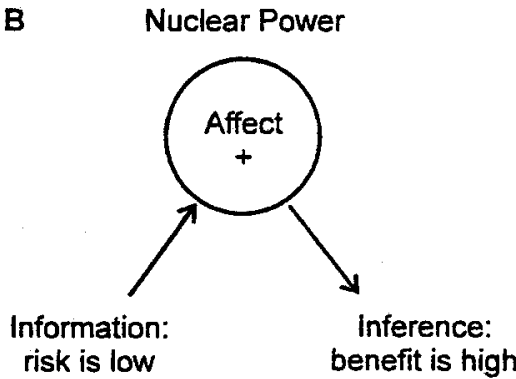

D

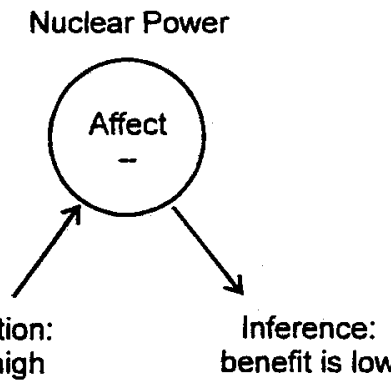

Exhibit 4. Model showing how information about benefit (A) or information about risk (B) could increase the global affective evaluation of nuclear power and lead to inferences about risk and benefit that are affectively congruent with the information input. Similarly, information could decrease the global affective evaluation of nuclear power as in $\mathrm{C}$ and $\mathrm{D}$, resulting in inferences that are opposite those in $\mathrm{A}$ and $\mathrm{B}$ 
Exhibit 5. Manipulations of benefit and risk information and predicted effects on the nonmanipulated attribute

\begin{tabular}{lll}
\hline & Information content & Predicted effect on nonmanipulated attribute \\
\hline (1) & Benefit is high & Decrease perceived risk \\
(2) Benefit is low & Increase perceived risk \\
(3) Risk is high & Decrease perceived benefit \\
(4) Risk is low & Increase perceived benefit \\
\hline
\end{tabular}

perceived risk. Similarly, decreasing favorability by increasing perceived risk should lead to a decrease in judgments of benefit. These predictions are summarized in rows 2 and 3 of Exhibit 5 .

We can contrast these predictions, based upon the affect heuristic, with an alternative prediction derived from a cognitive analysis. Since care is taken in this design to provide information only about risk or only about benefit, it should be difficult for the respondent to analytically derive a congruent judgment (e.g. benefit is high) from the information given (e.g. risk is low). Therefore, one might expect the nonmanipulated attribute (benefit in this case) to remain unchanged upon receipt of information pertaining to the other attribute (risk in this case). This explanation would thus predict little or no systematic effect of the information on benefit, the nonmanipulated attribute.

\section{Method}

\section{Participants}

Two hundred and thirteen undergraduate students from the University of Oregon (mean age 21 years) participated in the study. Females constituted $49 \%$ of the sample.

\section{Design}

A mixed, 4 (affective information: high risk/low risk/high benefit/low benefit) $\times 3$ (technologies: nuclear power/natural gas/food preservatives) design was used, with the first factor between-subjects and the second factor within-subjects. Participants were randomly assigned to one of the four experimental conditions that corresponded to the use of vignettes designed to increase or decrease perceived risk and perceived benefit. The high-risk and high-benefit conditions each included 56 participants; for the low-risk and low-benefit conditions there were 54 and 53 participants, respectively. Three vignettes were given to participants in each condition: one each about nuclear power, natural gas, and food preservatives.

\section{Stimuli and procedure}

Participants completed a questionnaire as part of a larger series of judgment studies. Initially, ratings of each technology's benefits and risks were elicited. For example, participants were asked 'In general, how beneficial do you consider the use of natural gas to be to US society as a whole?' and made ratings on 10-point scales ranging from not at all beneficial to very beneficial. A similar question and scale was used for eliciting risk ratings.

Next, instructions indicated to participants that the subsequent pages contained some general information about the benefits (risks) associated with each of several technologies, and even though it was recognized that there were some risks (benefits) associated with these technologies, the latter would not be dealt with at this time (see the Appendix for examples from the nuclear power series). 
Participants were told that after they had read the information they would be asked to make several judgments about each technology. The questions and 10-point scales used to collect risk and benefit ratings following the vignettes were identical to those that preceded the vignettes.

\section{Results}

Ratings of risk and benefit before and after the information manipulation was presented were averaged across participants. The effect of the manipulation was assessed by (1) taking the mean difference in the ratings for the manipulated attribute and dividing by the standard error of the mean to produce a $t$ value, and (2) calculating a similar $t$-value for the nonmanipulated attribute.

For example, the brief paragraph about nuclear power given to 56 subjects in the low-risk condition (see Appendix) led the mean judged risk from nuclear power to decrease from 7.48 (prior to information) to 6.61 (post-information; $t=-2.54 ; p<0.01$. The judged benefits of nuclear power increased, as predicted, after receipt of the information about low risk, moving from 5.25 (prior to information) to 6.02 (post-information); $t=3.33 ; p<0.01$. All 12 such $t$-values (three technologies by four experimental conditions) are plotted in Exhibit 6. The affect model predicts that the nonmanipulated attribute would change in a direction affectively congruent with the manipulation. That is, if the manipulation was designed to decrease perceived risk, then perceived benefit should increase, etc., leading to an inverse relationship between the manipulated and nonmanipulated attributes. As predicted, the nonmanipulated attribute generally changed in the direction affectively congruent with the manipulation (the only exceptions were Food LB and Nuclear LB). The correlation across the 12 data points was -0.75 .

Perhaps more informative than the aggregated data in Exhibit 6 are the reactions of individual subjects to the information manipulations. Recall that each of the 219 subjects received three vignettes, making a total of $219 \times 3=657$ attempted manipulations of affect and response. As noted in the

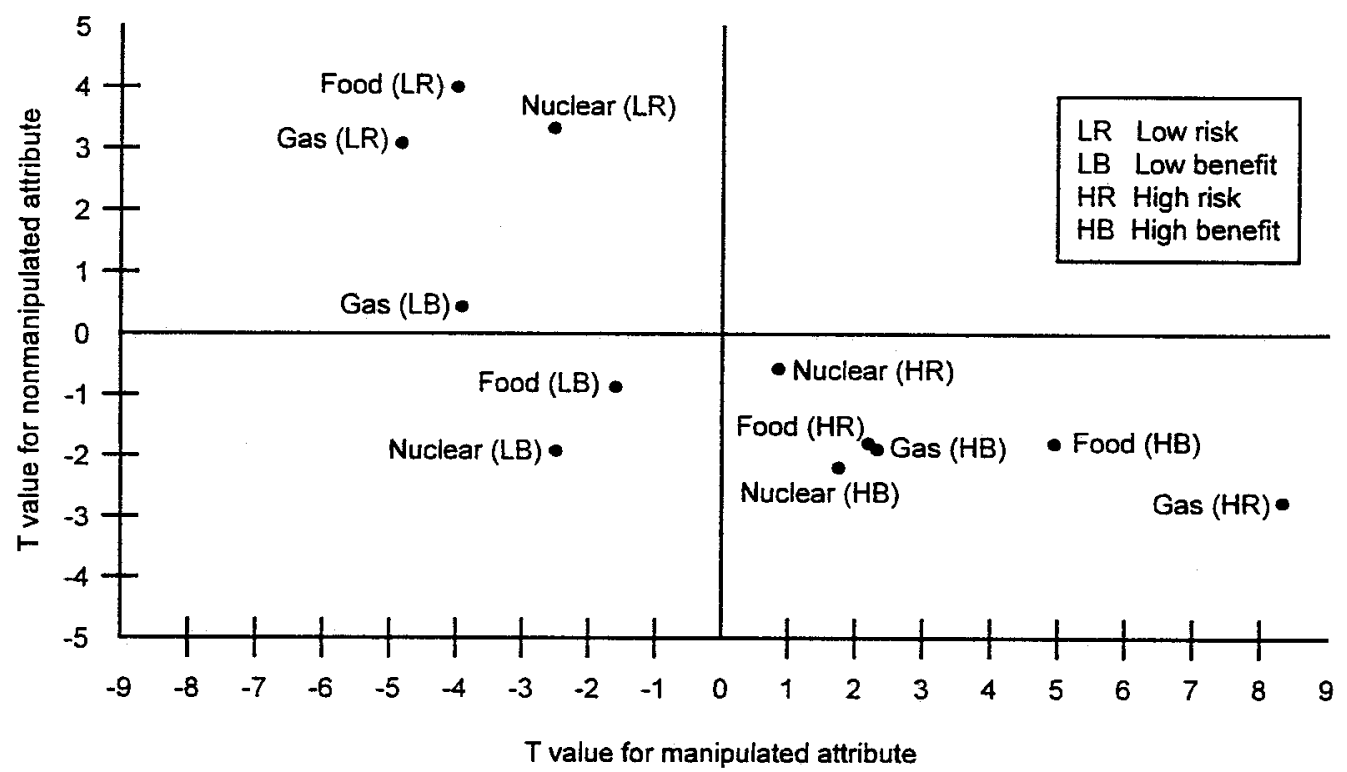

Exhibit 6. $T$-values for manipulated versus nonmanipulated attributes for four information manipulations (high risk, low risk, high benefit, and low benefit) about three technologies (nuclear power, natural gas, and food preservatives) 
Exhibit 7. Effect of the manipulation on the attribute that was manipulated

\begin{tabular}{lccc}
\hline Condition & $\begin{array}{c}\text { Percent of trials that } \\
\text { manipulation } \\
\text { worked }\end{array}$ & $\begin{array}{c}\text { Percent of trials that } \\
\text { effect was opposite } \\
\text { manipulation }\end{array}$ & $\begin{array}{c}\text { Percent of trials } \\
\text { no change }\end{array}$ \\
\hline High benefit & 50 & 16 & 34 \\
Low benefit & 47 & 19 & 35 \\
High risk & 47 & 18 & 35 \\
Low risk & 58 & 13 & 29 \\
Natural gas & 57 & 11 & 32 \\
Nuclear power & 45 & 21 & 34 \\
Food preservatives & 49 & 17 & 33 \\
Overall $(N=657)$ & 50 & 16 & 33 \\
\hline
\end{tabular}

Exhibit 8. Effect of the risk and benefit manipulations on judgments about the nonmanipulated attribute

\begin{tabular}{|c|c|c|c|}
\hline \multirow[b]{2}{*}{ Effect on the manipulated attribute } & \multicolumn{3}{|c|}{ Effect on the nonmanipulated attribute } \\
\hline & $\begin{array}{l}\text { Percent of } \\
\text { trials } \\
\text { prediction } \\
\text { confirmed }\end{array}$ & $\begin{array}{l}\text { Percent of } \\
\text { trials change } \\
\text { was opposite } \\
\text { of prediction }\end{array}$ & $\begin{array}{c}\text { Percent } \\
\text { of trials } \\
\text { no change }\end{array}$ \\
\hline $\begin{array}{l}\text { Manipulation worked } \\
\quad N=331(50.4 \%)\end{array}$ & $45^{\mathrm{a}}$ & 23 & 31 \\
\hline $\begin{array}{l}\text { No change } \\
\qquad N=218(33.2 \%)\end{array}$ & 20 & 15 & 64 \\
\hline $\begin{array}{l}\text { Change was contrary to manipulation } \\
\quad N=108(16.4 \%)\end{array}$ & 26 & 33 & 41 \\
\hline $\begin{array}{l}\text { Total } \\
\qquad N=657\end{array}$ & 34 & 22 & 44 \\
\hline
\end{tabular}

bottom row of Exhibit 7, the manipulation worked for $50 \%$ of the attempts (judgments of perceived risk increased after receipt of information saying risk was high; judgments of perceived benefit decreased after receipt of information saying benefit was low; etc.). The judgment remained unchanged after receipt of information for $33 \%$ of the attempts and the judgment changed in the wrong direction $16 \%$ of the time. The success of the manipulation was slightly higher in the low-risk condition $(58 \%)$ and for the natural gas information set $(57 \%)$. The manipulation was somewhat less successful for nuclear power $(45 \%)$.

Exhibit 8 shows the change in judgments regarding the nonmanipulated attribute, after the information manipulation occurred. Note that for the 331 cases in which the information worked as intended on the manipulated attribute, the effect on the nonmanipulated attribute was in the affectively congruent direction (as predicted) for $45 \%$ of the cases. There was no change in the nonmanipulated attribute for $31 \%$ of those cases and there was a change that went in the same direction as the manipulation (opposite the prediction) for $23 \%$ of the cases. In sum, when the information manipulation worked, the judgment of the nonmanipulated attribute tended to move in the predicted direction. The results clearly differ from what would be predicted from a cognitive model that 
recognized the lack of direct relevance between the information provided about risk (or benefit) and the judgment requested regarding the nonmanipulated attribute.

The predicted response was much less frequent when the manipulation failed to cause a change in judgment (in Exhibit 8, compare the first column of data in row 2 with the first data column in row 1). Interestingly, when the information produced a change in the manipulated attribute that was in the wrong direction (row 3 of the table), the judgment of the nonmanipulated attribute moved in a direction opposite (but effectively congruent with) the change in the first judgment on $33 \%$ of the occasions, giving further indication of the tendency for risk and benefit judgments to move in inverse relationship to one another. ${ }^{4}$

\section{Discussion}

The results of Study 2 confirmed the prediction that evaluative judgments on one affective attribute can be influenced by experimentally manipulating information on another affective attribute. The findings are generally consistent with the idea that people use the affect heuristic to make judgments about risk and benefit.

Importantly, Study 2 showed that the inverse relationship between perceived risk and perceived benefit found in Study 1 and other previous studies (e.g. Alhakami and Slovic, 1994) is causally determined. That is, the study demonstrated a causal relationship by means of a direct experimental manipulation of risk and benefit. When the manipulation worked (i.e. when information increased perceived risk or benefit) the expected affectively congruent but inverse effect was found on the nonmanipulated attribute (i.e. perceived benefit or risk decreased).

The results demonstrate a phenomenon in risk perception that is similar to the halo effect, a tendency toward affectively consistent judgments. Previous researchers have found that the favorability of the overall impression of an attitude object is a good predictor of how strongly positive or negative qualities are ascribed to the object (Klauer and Stern, 1992). For example, an object judged favorably overall tends to be given more positive than negative evaluations on specific dimensions. The results of the present study demonstrate a similar effect: changing people's perception of one attribute (e.g. increasing risk) tended to influence ratings on another attribute (e.g. decreasing benefit). Thus, a confounding between risk and benefit judgments is revealed, which we believe occurs because people are consulting their overall affective evaluation of the item when judging its risk and benefit.

\section{GENERAL DISCUSSION}

In this paper we have used two different approaches to study the affect heuristic. Neither approach rules out the use of cognitive strategies by individuals, but together the studies strongly suggest that affect plays an important role in the types of risk/benefit judgments investigated here. We do not claim that this paper represents a comprehensive or exhaustive approach, merely a beginning. Ultimately, synthesis of findings from diverse methodologies will clarify our understanding of the role of affect in judgment. For now, the present studies highlight the importance of considering affect in judgment processes, and specifically suggest that the inverse relationship between risk and benefit judgments can be explicated at least partially by reference to the affect heuristic.

\footnotetext{
${ }^{4}$ An example of this would be the case where information indicating that the risk of nuclear power was low led a subject to increase his or her judgment of the risk from nuclear power (a change contrary to the manipulation) and then to decrease the judged benefit of nuclear power. The benefit judgment moved in a direction opposite of that predicted by the information manipulation, but it changed in a way that was affectively consistent with the increased judgment of nuclear risk.
} 
The present studies present two lines of evidence suggesting that risk and benefit are linked in people's perceptions and consequently in their judgments. The first line shows strong inverse relationships between risk and benefit judgments for hazards with qualitatively different risks and benefits; the second line shows the influence of information about one attribute of hazards (either risk or benefit) on judgments about the other unmentioned attribute. Based on recent work emphasizing the crucial role in judgment of images marked by positive and negative feelings (Damasio, 1994), and research documenting the fundamental influence of affect as a motivator of behavior (Epstein, 1994; Mowrer, $1960 \mathrm{a}, \mathrm{b})$, it is plausible that perceived risk and benefit are linked via some sort of affective commonality. Specifically, a parsimonious explanation is that the positive and negative feelings attached to the images people associate with hazards are available and influential when risk and benefit are judged. That is, representations of objects and events in people's minds are tagged to varying degrees with affect, and the affective pool is consulted to make quick evaluations. In this way, judgments of risk and benefit are guided and linked by affect. Reliance on affect probably ebbs and flows according to various contextual factors, including the extent to which stimuli evoke images that are tagged clearly with positive or negative feelings. Which situations are most influenced by the affect heuristic is an empirical question.

Future researchers need to explore more deeply the underlying affective mechanisms by which judgments are made, as well as the interplay between affect and cognition in reasoning. One suggestion is that researchers examine the relationship between the affect and availability heuristics. To date the availability heuristic has been portrayed typically as a cognitive judgment strategy, in that it works by increasing deliberation about reasons that bias probability judgments. However, the reasons that come to mind may be analytic, or tinged with positive and negative affective tags, or both. Thus, the availability heuristic may be working through cognitive or affective processes. The extent to which each process is evoked is unclear; the challenge is to begin hypothesizing about and testing models of judgment that elucidate the roles of both cognition and affect.

\section{APPENDIX: VIGNETTES ABOUT NUCLEAR POWER FOR AFFECTIVE INFORMATION MANIPULATIONS IN STUDY 2}

\section{High-risk condition}

Nuclear power creates significant hazards to human health. Because each plant requires tons of enriched uranium to operate, the nuclear fuel cycle produces radioactive hazards and waste at every stage. Radiation hazards start with mining and milling, continue through fabrication, to transportation, to operation and finally to waste storage. In addition, the plants themselves are extremely complicated and can fail in ways that are both hard to predict and impossible to control. The accidents at Three Mile Island and at Chernobyl illustrate the dangers of plant operation. Even more serious accidents have been narrowly avoided in the past and could occur in the future. Finally, after the nuclear plants that created the waste have served out their life and been shut down, the waste they generated will need to be stored and protected for thousands of years. This waste is highly radioactive and contaminated with plutonium, a deadly element that can be reprocessed from such waste and turned into nuclear weapons.

\section{Low-risk condition}

Nuclear power has a good safety record and an accident rate that is comparable with other industries that produce electricity. Part of the reason that risks have been low in the nuclear power industry is that the industry is heavily monitored and regulated by the federal government. All nuclear power plants 
have on-site federal regulators. The plants are also built to resist accidents. Even the most serious nuclear accident in US history, Three Mile Island, did not harm anyone's health.

\begin{abstract}
High-benefit condition
Nuclear power has many advantages over other methods of producing electricity. For example, nuclear power does not depend on a diminishing supply of fossil fuels, as do coal, oil, and natural-gas power plants. Consequently, nuclear power can be produced without dependence on oil imports from distant countries.

Nuclear power can be produced in an almost unlimited amount. It already produces a substantial proportion of all electricity used in the United States. As our society grows and develops, nuclear power will be able to meet increasing demands for electricity and thus contribute greatly to our nation's economic development and prosperity.
\end{abstract}

\title{
Low-benefit condition
}

Nuclear power today produces only a small percentage of our nation's electricity. New methods of generating electricity, such as geothermal, solar power, and wind turbines, could eventually replace nuclear power. In addition, the application of energy-conservation methods could save more energy than is produced by nuclear power. Finally, the addition of electrical generators to the boilers of factories all over the United States could produce more power than is supplied by nuclear power, without the construction of any more power plants of any sort.

\section{ACKNOWLEDGEMENTS}

This research was supported by the US National Science Foundation under Grants SBR 9422754 and SBR 9709307 to the Decision Science Research Institute, Inc. We are grateful to the Department of Psychology, University of Western Australia, for the laboratory space and equipment used in Study 1. We thank Sarah Lichtenstein, Lisa Ordóñez, and two anonymous reviewers for valuable comments on the manuscript and CK Mertz for assistance with the data analysis. We also thank Janet Douglas and Leisha Mullican for their assistance in preparation of the manuscript.

\section{REFERENCES}

Alhakami, A. S. and Slovic, P. 'A psychological study of the inverse relationship between perceived risk and perceived benefit', Risk Analysis, 14(6) (1994), 1085-1096.

Beach, L. R. and Mitchell, T. R. 'A contingency model for the selection of decision strategies', Academy of Management Review, 3 (1978), 439-449.

Benson, L., III and Beach, L. 'The effects of time constraints on the pre-choice screening of decision options', Organizational Behavior and Human Decision Processes, 67 (1996), 222-228.

Busemeyer, J., Hastie, R. and Medin, D. L. (eds) Decision Making from a Cognitive Perspective, San Diego: Academic Press, 1995.

Damasio, A. R. Descartes’ Error: Emotion, Reason, and the Human Brain, New York: Avon, 1994.

Dijker, A. J. and Koomen, W. 'Stereotyping and attitudinal effects under time pressure', European Journal of Social Psychology, 26 (1996), 61-74.

Edland, A. and Svenson, O. 'Judgment and decision making under time pressure', in O. Svenson and J. Maule (eds), Time Pressure and Stress in Human Judgment and Decision Making (pp. 27-40), New York: Plenum, 1993. 
Epstein, S. 'Integration of the cognitive and psychodynamic unconscious', American Psychologist, 49 (1994), $709-724$

Finucane, M. L., Maybery, M. T. 'Risk perceptions in Australia', Psychological Reports, 79 (1996), 1331-1338.

Fischhoff, B., Slovic, P., Lichtenstein, S., Read, S. and Combs, B. 'How safe is safe enough: A psychometric study of attitudes towards technological risks and benefits', Policy Sciences, 9 (1978), 127-152.

Guthrie, E. R. The Psychology of Learning, (rev. edn), New York: Harper \& Bros, 1952.

Kerstholt, J. H. 'The effect of time pressure on decision-making behaviour in a dynamic task environment', Acta Psychologica, 86 (1994), 89-104.

Klauer, K. C. and Stern, E. 'How attitudes guide memory-based judgments: a two-process model', Journal of Experimental Social Psychology, 28 (1992), 186-206.

Maule, A. J. and Svenson, O. (eds) 'Concluding remarks', in Time Pressure and Stress in Human Judgment and Decision Making (323-329), New York: Plenum, 1993.

McDaniels, T. L., Axelrod, L. J., Cavanagh, N. S. and Slovic, P. 'Perception of ecological risk to water environments', Risk Analysis, 17 (1997), 341-352.

Montgomery, H. 'Decision rules and the search for a dominance structure: towards a process model of decision making', in Humphreys, O. Svenson and A. Vari (eds), Analysing and Aiding Decision Processes (343-369), Amsterdam: North-Holland, 1983.

Mowrer, O. H. Learning Theory and Behavior, New York: Wiley, 1960a.

Mowrer, O. H. Learning Theory and the Symbolic Processes, New York: Wiley, 1960b.

Ordóñez, L. and Benson, L., III 'Decisions under time pressure: how time constraint affects risky decision making', Organizational Behavior and Human Decision Processes, 71 (1997), 121-140.

Payne, J. W., Bettman, J. R. and Johnson, E. J. 'Adaptive strategy selection in decision making', Journal of Experimental Psychology: Learning, Memory, and Cognition, 14 (1988), 534-552.

Payne, J. W., Bettman, J. R. and Johnson, E. J. 'Behavioral decision research: a constructive processing perspective', Annual Review of Psychology, 43 (1992), 87-131.

Payne, J., Bettman, J. and Johnson, E. The Adaptive Decision Maker, New York: Cambridge University Press, 1993.

Peters, E. and Slovic, P. 'The role of affect and worldviews as orienting dispositions in the perception and acceptance of nuclear power', Journal of Applied Social Psychology, 26 (1996), 1427-1453.

Rohrmann, B. 'Risk perception of different societal groups: Australian findings and cross-national comparisons', Australian Journal of Psychology, 46 (1994), 150-163.

Shafir, E., Osherson, D. and Smith, E. 'An advantage model of choice', Journal of Behavioral Decision Making, 2 (1989), 1-23.

Shafir, E., Simonson, I. and Tversky, A. 'Reason-based choice', Cognition, 49 (1993), 11-36.

Simon, H. 'Rational choice and the structure of the environment', Psychological Review, 63 (1956), 129-138.

Slovic, P. 'The construction of preference', American Psychologist, 50 (1995), 364-371.

Slovic, P. 'Trust, emotion, sex, politics, and science: surveying the risk-assessment battlefield', in M. H. Bazerman, D. M. Messick, A. E. Tenbrunsel and K. A. Wade-Benzoni (eds), in Environment, Ethics, and Behavior (277313), San Francisco: New Lexington, 1997.

Slovic, P., Kraus, N., Lappe, H. and Major, M. 'Risk perception of prescription drugs: report on a survey in Canada', Canadian Journal of Public Health, 82 (1991), S15-S20.

Svenson, O., Edland, A. and Slovic, P. 'Choices and judgments of incompletely described decision alternatives under time pressure', Acta Psychologica, 75 (1990), 153-169.

Tetlock, P. E., Skitka, L. and Boettger, R. 'Social and cognitive strategies for coping with accountability: conformity, complexity, and bolstering', Journal of Personality and Social Psychology, 57 (1989), 632-640.

Tversky, A. 'Elimination by aspects: a theory of choice', Psychological Review, 79 (1972), 281-299.

Tversky, A. and Kahneman, D. 'Judgment under uncertainty: heuristics and biases', Science, 185 (1974), $1124-1131$.

Zajonc, R. B. 'Feeling and thinking: preferences need no inferences', American Psychologist, 35 (1980), 151-175. 
Authors' biographies:

Melissa L. Finucane is a Visiting Research Associate at Decision Research, Eugene, Oregon, and a Visiting Scholar at the Institute for Cognitive and Decision Sciences, University of Oregon. Her research interests include judgment, decision making, affect, and risk perception.

Ali Alhakami is on the psychology faculty of Imam Muhammad Ibn Saud Islamic University of Riyadh, Saudi Arabia. His interests include judgment, decision making, and social cognition.

Paul Slovic is President of Decision Research and Professor of Psychology at the University of Oregon. His research interests include judgment, decision making, and risk analysis.

Stephen M. Johnson is a research associate at Decision Research and Associate Director of the University of Oregon Survey Research Laboratory. His interests include perceptions of technological risk, nature, and the environment.

Authors' addresses:

Melissa L. Finucane, Paul Slovic and Stephen M. Johnson, Decision Research, Eugene, OR 97401, USA.

Ali Alhakami, Imam Muhammad Ibn Saud Islamic University Psychology Department, PO Box 15593, Riyadh 11454, Saudi Arabia. 